\title{
Solubility Enhancement of Embelin by Complexation with Beta Cyclodextrin
}

\author{
Jashna K Kani, Elizabeth N Xavier* \\ Department of Pharmaceutics, Nirmala College of Pharmacy, Muvattupuzha, Ernakulam, Kerala, INDIA.
}

\begin{abstract}
Introduction: Embelin, a phytoconstituent obtained from Embelia ribes of the Myrsinaceae family, has anti-cancer, anti-inflammatory, anti-bacterial, anti-fertility, analgesic, antidiabetic, anti-depressant and wound healing activities. It is hydrophobic in nature leading to low bioavailability. Aim: The present study aims to improve the water solubility and rate of dissolution of Embelin by complexation with $\beta$-cyclodextrin. Methods: Inclusion complexes were prepared by physical mixture, kneading and co-precipitation methods. Characterization of complexes was carried out by Fourier-Transform Infrared (FT-IR) spectroscopy and in vitro dissolution study. Differential scanning calorimetry (DSC) and Scanning electron microscopy (SEM) was used to analyze the prepared complexes prepared by the co-precipitation method. Antimicrobial studies of complexes against Staphylococcus aureus and Escherichia coli were carried out by colony counting method. Results: Phase solubility study showed Embelin forms complex with $\beta$-cyclodextrin in the ratio 1:2. FT-IR studies of complexes confirmed Embelin forms complex with $\beta$-cyclodextrin. DSC and SEM also confirmed the formation of a complex of Embelin with $\beta$-cyclodextrin. In vitro dissolution studies showed that the time to release $50 \%$ (t50) of Embelin was in the order $15 \mathrm{~min}, 30 \mathrm{~min}, 60 \mathrm{~min}$ for complexes prepared by coprecipitation, kneading method and physical mixture respectively. Complexes prepared by the coprecipitation method showed 2 log reductions in the number of $S$. aureus and $1 \mathrm{log}$ reduction in the number of $E$. coli in comparison with Embelin. Conclusion: Complexes of Embelin prepared by co-precipitation method resulted in largest percent drug content, enhanced aqueous solubility and antibacterial activity.
\end{abstract}

Key words: Embelin, $\beta$-cyclodextrin, Inclusion complexes, Solubility, Co-precipitation method.

\section{INTRODUCTION}

Potential health benefits and less toxicity of natural products made them the first choice for the search for new drugs. ${ }^{1}$ Embelin (Figure 1) is a phytoconstituents obtained from the plant Embelia ribes from the Myrsinaceae family. ${ }^{2,3}$ It has anticancer, ${ }^{4}$ anti-inflammatory, ${ }^{5}$ anti-bacterial, ${ }^{6}$ antifertility, ${ }^{7}$ analgesic, ${ }^{8}$ antidiabetic, ${ }^{9}$ antidepressant, ${ }^{10}$ and wound healing activities. ${ }^{11}$ Molecular weight of Embelin is 294.391 $\mathrm{g} / \mathrm{mol}$ and melting point is $142.5^{\circ} \mathrm{C}$. It is lipophilic in nature with a $\log \mathrm{P}$ of $4.34{ }^{12}$ Embelin has low solubility ${ }^{13}$ in water $(0.2-0.3 \mathrm{mg} / \mathrm{ml})^{14}$ and less bioavailability $(30 \pm 11 \%)^{2} \quad$ It is a 2,5-dihydroxy-3undecyl-1, 4-benzoquinone. ${ }^{7}$
Cyclodextrins (CDs) are obtained from the enzymatic degradation of starch. ${ }^{15}$ They can form complexes with drug molecules which is favored by cyclodextrin's unique ring structure made by binding of glucose units. Such complexes can improve the physicochemical properties of drugs without changes in their molecular level ${ }^{16}$ rendering the name 'enabling pharmaceutical ingredients' for cyclodextrins. ${ }^{17}$ The $\alpha, \beta$ and $\gamma$-CD cyclodextrins are composed of six, seven and eight D-(+) -glucopyranose units $^{18}$ respectively. Present study uses $\beta$-cyclodextrin which is cheap, biocompatible, possesses adequate cavity
Submission Date: 10-08-2020; Revision Date: 27-02-2021; Accepted Date: 12-04-2021

DOI: 10.5530/ijper.55.2s.112 Correspondence: Mrs. Elizabeth N Xavier, M.Pharm

Associate Professor, Department of Pharmaceutics, Nirmala College of Pharmacy, Muvattupuzha, Ernakulam-686661, Kerala, INDIA.

Phone: +91-0485-2562782 Email id: elsuonline4chat@ gmail.com

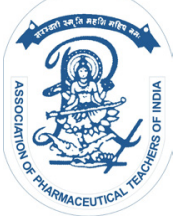

www.ijper.org 


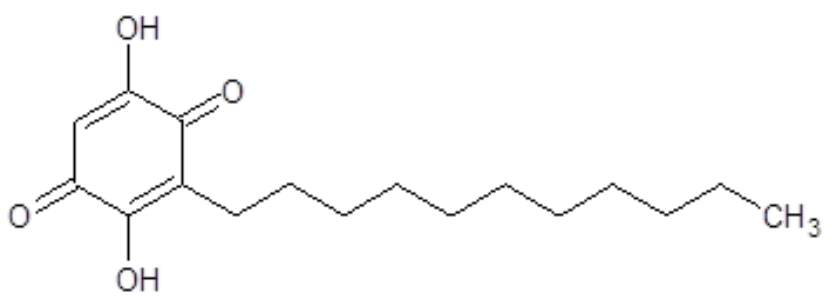

Figure 1: Structure of Embelin.

size and effective drug complexation. ${ }^{19}$ Drug permeation through biological membranes can be enhanced by the formation of water-soluble inclusion complexes. ${ }^{20}$ The amount of CD has to be optimum for maximum permeation. Kneading and co-precipitation are the two most commonly used methods for the preparation of inclusion complexes. CDs have the potential for the delivery of poorly soluble drugs to the body. So, they can be used as a tool to deliver active pharmacophores that lack the required physicochemical attributes for optimum bioavailability to the body. ${ }^{21}$ Drugs encapsulated in particulate systems in the presence of CDs have shown improved permeability and bioavailability. ${ }^{22}$ Layered tablets based on CDs has been developed for nonsteroidal anti-inflammatory drugs. ${ }^{23} \mathrm{CDs}$ can modify the release of drugs from different drug delivery systems. ${ }^{24}$ Cyclodextrins based formulations for improving patient compliance have been reported. ${ }^{25}$

In order to increase its solubility and thereby bioavailability, Embelin is complexed with cyclodextrin to form inclusion complexes. Evaluation of prepared complexes can confirm the formation of complexes. It also reveals the extent of solubility enhancement of Embelin and modifications in its antimicrobial activity.

\section{MATERIALS}

Embelin (YUCCA enterprises with a certificate of analysis having the purity of $98 \%$, Mumbai, Maharashtra), $\beta$-cyclodextrin (Chemdyes Co-operation, Rajkot, Gujarat), Mc Farland turbidity standard (Chemdyes Co-operation, Rajkot, Gujarat), Nutrient broth (HiMedia laboratories private Ltd, Bengaluru, Karnataka), Agaragar (Research lab fine chem industries, Mumbai, Maharashtra), Sodium hydroxide (Nice chemicals, Kochi), Potassium dihydrogen phosphate (Nice chemicals, Kochi), Methanol (Nice chemicals, Kochi), Whatman filter paper $(0.45 \mu \mathrm{m})$, Escherichia coli (ATCC 8739), Staphylococcus aureus (ATCC 6538P) (NCIM, CSIR, Pune, Maharashtra).

\section{METHODS}

\section{Phase solubility studies}

Higuchi and Connors method was used to carry out phase solubility studies. ${ }^{26}$ Excess amounts of Embelin was added to vials containing $\beta$-cyclodextrin solution $(5 \mathrm{ml})$ in a mixture of methanol and water $(25 / 75 \mathrm{v} / \mathrm{v})$ at a different concentration ranging from $0.1 \times 10^{-2} \mathrm{M}$ to $1.0 \times 10^{-2} \mathrm{M}$. The vials were shaken at $32^{\circ} \mathrm{C}$ for $48 \mathrm{~h}$. Centrifuge the sample for $10 \mathrm{~min}$ at $3000 \mathrm{rpm}$. The resulting solution was then filtered through Whatman filter paper size $(0.45 \mu \mathrm{m})$ and analyzed by UV-Visible spectrophotometer at $324.6 \mathrm{~nm} \cdot{ }^{27,28}$

\section{Preparation of complexesPhysical mixture}

The required molar ratio (1:2) quantities of the Embelin and $\beta$-cyclodextrin were accurately weighed and mixed for $45 \mathrm{~min}$ by trituration in a mortar. The mixture was passed through sieve No: 44 and stored in airtight containers. ${ }^{29}$

\section{Kneading method}

Embelin and $\beta$-cyclodextrin were weighed in the ratio of 1:2. Added small quantities of water and methanol (1:2) mixture till a homogeneous paste was obtained. To this Embelin powder was added in portions and kneading was continued for one hour. Paste consistency was maintained by adding a methanol-water mixture. A hot air oven was used to dry the prepared paste at $45^{\circ}$ $50^{\circ} \mathrm{C}$ for $24 \mathrm{~h}$. Product was passed through sieve No: 44 and stored in airtight containers. ${ }^{29,30}$

\section{Co-precipitation method}

Weighed Embelin and $\beta$-cyclodextrin in the molar ratio (1:2). Dissolved the weighed ingredients in methanol: water. The Embelin solution was added drop-wise into cyclodextrin solution. Stirring was continued for $6 \mathrm{~h}$ in a mechanical shaker. The product was dried at $45-50^{\circ} \mathrm{C}$ for $48 \mathrm{~h}$ and stored in airtight containers. ${ }^{29}$

The percentage yield ${ }^{30}$ of the prepared complex was also determined using the formula

Percentage yield $=\frac{\text { Practical yield }}{\text { Theoretical yield }} \times 100$

\section{Fourier-transform infrared spectroscopy (FT-IR)}

FT-IR spectrum of standard Embelin and inclusion complexes was obtained by using FT-IR Spectrophotometer, Nicolet-iS5 [Id3 ATR-Ge], Thermo scientific, USA. The scans were obtained from 4000 to $400 \mathrm{~cm}^{-1}$ at a resolution of $1 \mathrm{~cm}$. 


\section{Differential scanning calorimetry (DSC)}

DSC analyzer (TA INSTRUMENTS Q 20 USA) was used to perform DSC analysis of Embelin, $\beta$-cyclodextrin and inclusion complexes prepared by co-precipitation method. A sample $(5 \mathrm{mg})$ was sealed in an aluminum pan and subjected to heating at a rate of $10^{\circ} \mathrm{C} / \mathrm{min}$ from $25-250^{\circ} \mathrm{C}$ under a nitrogen atmosphere.

\section{Scanning electron microscopy (SEM)}

Scanning electron microscope (SEM-JOEL Instruments, JSM-7610F, Japan) was used for studying surface morphology of inclusion complex prepared by co-precipitation method. After mounting the samples on the aluminum stub, they are dried at $37^{\circ} \mathrm{C}$. Then it is coated with a thin gold-ion layer $(3 \mathrm{~nm})$ using a sputter coated unit. An acceleration voltage of $15 \mathrm{kV}$ was applied and the micrographs were examined at $\times 1000$ and $\times 5000, \times 10000, \times 20000$ magnifications.

\section{Percent drug content estimation}

Weighed complex equivalent to $5 \mathrm{mg}$ drug was transferred to $100 \mathrm{ml}$ standard flask. Made up the solution with phosphate buffer of $\mathrm{pH} 7.4$ and after UV absorbance was measured at $339.2 \mathrm{~nm}$ using UV-Visible spectrophotometer. ${ }^{31}$

\section{In vitro dissolution studies}

In vitro dissolution studies were carried out for pure Embelin and the inclusion of $\mathrm{CD}$ complexes to compare the solubility of complexes prepared by different methods. US Pharmacopeia Type I dissolution test apparatus was used for the study. CD complexes equivalent to contain $10 \mathrm{mg}$ Embelin were placed in dissolution vessels containing $900 \mathrm{ml}$ of phosphate buffer of $\mathrm{pH} 7.4 \mathrm{kept}$ at $37 \pm 0.5^{\circ} \mathrm{C}$ and stirred at 50 $\mathrm{rpm}$. Samples were collected periodically and replaced with a fresh dissolution medium. $10 \mathrm{ml}$ was withdrawn and filtered through Whatman filter paper. Absorbance was read at $339.2 \mathrm{~nm}$ against a blank. ${ }^{30-32}$

\section{Antibacterial studies}

The colony counting method was used for the evaluation of antibacterial activity against E. coli and $S$. aureus. E. coli (ATCC 8739) and $S$. aureus (ATCC 6538P) cells were grown $24 \mathrm{~h}$ on a shaker at $100 \mathrm{rpm}$ and $37^{\circ} \mathrm{C}$. Using $0.5 \mathrm{Mc}$ Farland turbidity standard $\left(1-2 \times 10^{8} \mathrm{CFU} /\right.$ $\mathrm{ml}$ ) as standard, bacterial suspensions were prepared in phosphate buffer solution (PBS) to get a density of $1 \times 10^{8}$ colony forming units (CFU)/ml. $100 \mathrm{mg}$ of UV sterilized Embelin and inclusion complexes were then added to the bacterial suspension. The media was incubated at $37^{\circ} \mathrm{C}$ for $24 \mathrm{~h}$. Bacterial culture was diluted in PBS. Nutrient agar plates were spread with this culture and incubated at $37^{\circ} \mathrm{C}$ overnight. Counted the CFU/ $\mathrm{ml}$. The experiments were performed in duplicate and the results are given as mean \pm standard deviation. The following equation was used to calculate the antibacterial activity of complexes

Percent Antibacterial activity $=(\mathrm{X}-\mathrm{Y}) / \mathrm{X} * 100$

Where $\mathrm{X}$ is the number of colonies $(\mathrm{CFU} / \mathrm{ml})$ in the control group, $\mathrm{Y}$ is the number of colonies after the Embelin/CD complex was added. ${ }^{33}$

\section{RESULTS}

\section{Phase solubility studies}

Using Higuchi and Connors method ${ }^{21}$ it was found that Embelin forms complex $\beta$-cyclodextrin within the ratio 1:2. The results are given in Table 1 . The phase solubility diagram is shown in Figure 2.

The percentage yield of the prepared inclusion complexes was $96.35 \%, 67 \%$ and $82 \%$ for physical mixture, kneading method and co-precipitation method respectively.

\section{Fourier-transform infrared spectroscopy (FT-IR)}

The characteristic peak of Embelin (Figure 7) was observed at $3295 \mathrm{~cm}^{-}, 2857 \mathrm{~cm}^{-}$and $2922 \mathrm{~cm}^{-}, 1680 \mathrm{~cm}^{-}$, $1117 \mathrm{~cm}^{-}$and $1320 \mathrm{~cm}^{-}$due to $\mathrm{O}-\mathrm{H}$ stretching, $\mathrm{C}-\mathrm{H}$ stretching vibration, presence of alkene and alcoholic $\mathrm{C}-\mathrm{O}$ bond respectively. The peaks of $\beta$-cyclodextrin (Figure 4) were seen at $3301 \mathrm{~cm}^{-}, 1619 \mathrm{~cm}^{-}, 1490 \mathrm{~cm}^{-}$, $1320 \mathrm{~cm}^{-}$and $1360 \mathrm{~cm}^{-}, 1150 \mathrm{~cm}^{-}, 1028 \mathrm{~cm}^{-}$due to $\mathrm{O}-\mathrm{H}$ stretching, an amide bond, $\mathrm{O}-\mathrm{H}$ bending, $\alpha-\mathrm{CH}_{2}$ bending, O-H bending $\mathrm{C}-\mathrm{C}-\mathrm{C}$ bonding respectively. The peaks for inclusion complexes prepared by physical

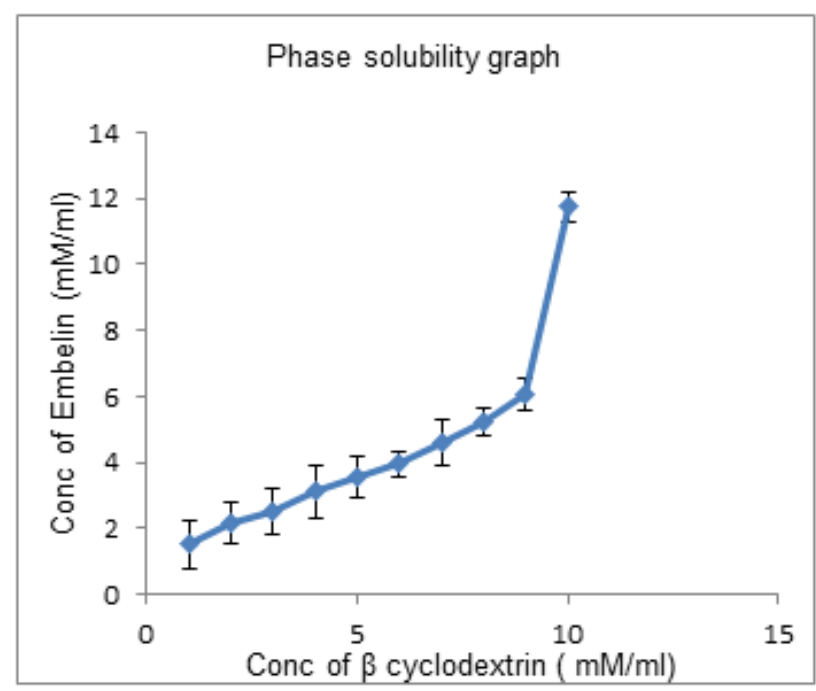

Figure 2: Phase solubility graph. 


\begin{tabular}{|c|c|}
\hline \multicolumn{2}{|c|}{ Table 1: Phase solubility studies. } \\
\hline $\begin{array}{c}\text { Concentration of } \boldsymbol{\beta} \\
\text { cyclodextrin }(\mathrm{mM} / \mathrm{ml})\end{array}$ & Concentration of Embelin( $\mathrm{mM} / \mathrm{ml})$ \\
\hline 1 & $1.514 \pm 0.722$ \\
\hline 2 & $2.157 \pm 0.645$ \\
\hline 3 & $2.533 \pm 0.708$ \\
\hline 4 & $3.117 \pm 0.788$ \\
\hline 5 & $3.588 \pm 0.633$ \\
\hline 6 & $3.956 \pm 0.384$ \\
\hline 7 & $4.606 \pm 0.712$ \\
\hline 8 & $5.236 \pm 0.438$ \\
\hline 9 & $6.083 \pm 0.486$ \\
\hline 10 & $11.741 \pm 0.456$ \\
\hline
\end{tabular}

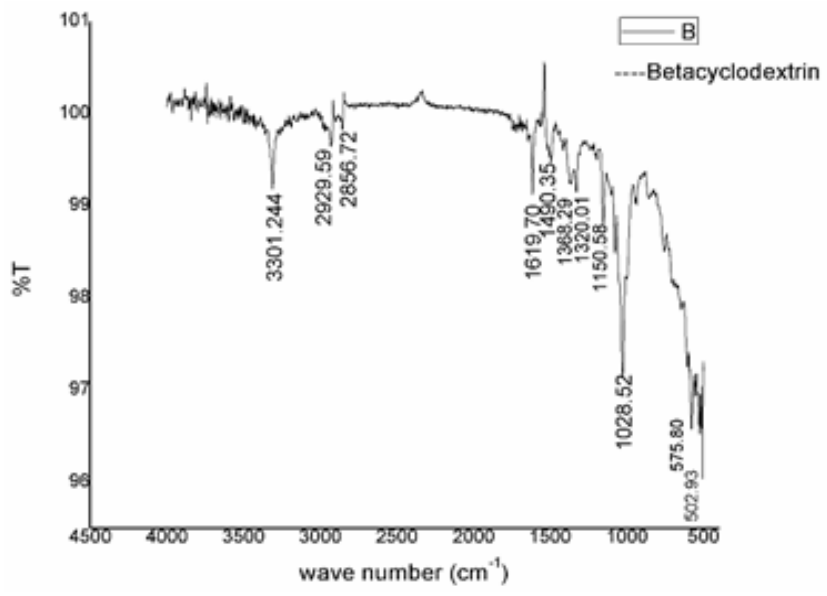

Figure 4: FT-IR spectrum of $\square$ cyclodextrin.

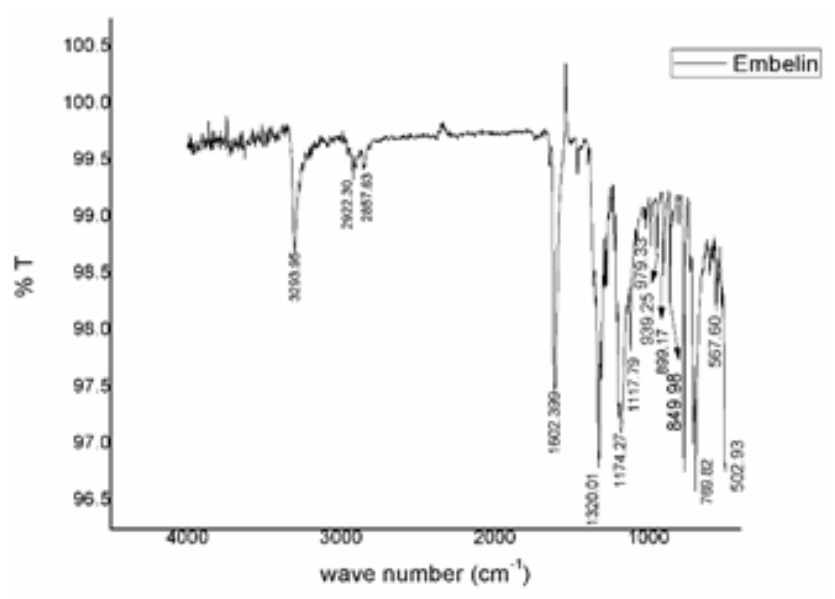

Figure 3: FT-IR spectrum of Embelin.

mixtures, kneading method and co-precipitation method were depicted in Figure 3, 5, 6 respectively.

\section{Differential scanning calorimetric (DSC) analysis}

The endothermic peaks for Embelin (Figure 8) are observed at $142.19^{\circ} \mathrm{C}, 86.87^{\circ} \mathrm{C}$ and $78.9^{\circ} \mathrm{C}$. The peak is observed at $110.7^{\circ} \mathrm{C}$ for $\beta$-cyclodextrin (Figure 9). Complexes prepared by the co-precipitation method show peaks at $218.5^{\circ} \mathrm{C}, 101.2^{\circ} \mathrm{C}$ (Figure 10).

\section{Scanning electron microscopic (SEM) analysis}

SEM image of inclusion complexes prepared by the co-precipitation method is shown in Figure 11.

\section{Percent drug content}

The percent drug content of prepared inclusion complexes was $48.69 \pm 0.774 \%$ for physical mixture, $84.90 \pm 0.486 \%$ for kneading method and $96.14 \pm$ $0.341 \%$ for the co-precipitation method.

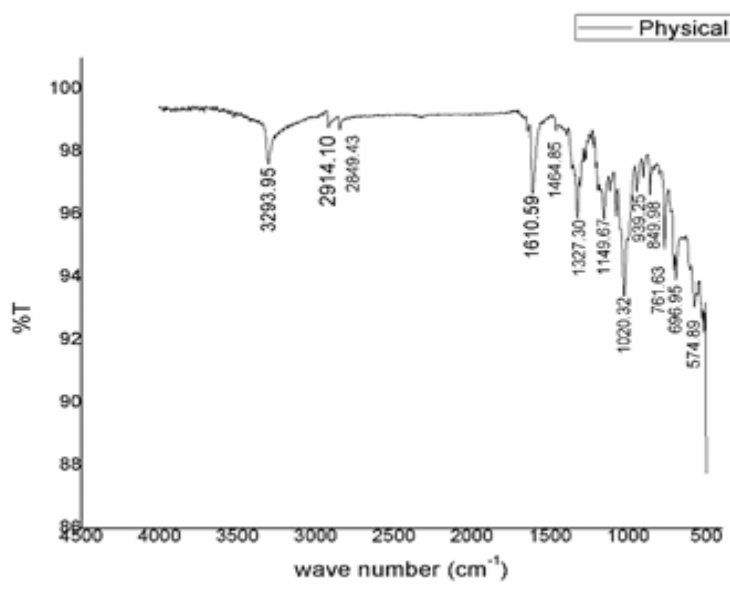

Figure 5: FT-IR spectrum of physical mixture.

\section{In vitro dissolution study}

The percent release of Embelin from complexes prepared by physical mixture, kneading method and co-precipitation method is shown in Table 2 and plotted in the graph Figure 12. Results for pure Embelin are also shown.

\section{Antibacterial activity}

The results of antibacterial activity are given as a log CFU graph in the Figure 13 and percent antibacterial activity is depicted in Table 3.

\section{DISCUSSION}

When the solubility of the Embelin increases with increasing $\beta$-cyclodextrin concentration A-type phase solubility profiles are obtained. ${ }^{25}$ Phase solubility profiles are $A_{p}$ - the type which indicates solubility of Embelin increases with an increase in $\beta$ - cyclodextrin concentration and Embelin form a complex with cyclodextrin in the ratio $1: 2$. 


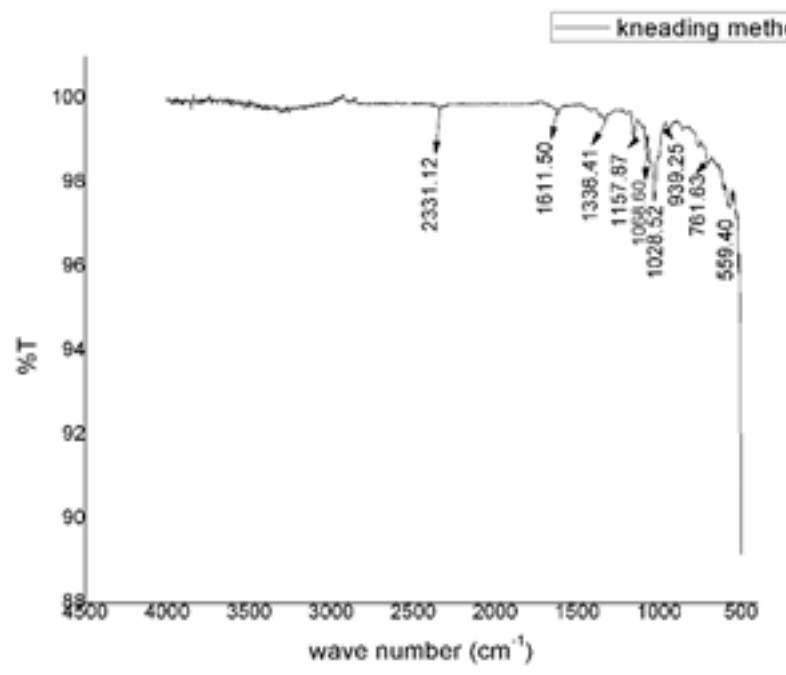

Figure 6: FT-IR spectrum of complexes prepared by kneading method.

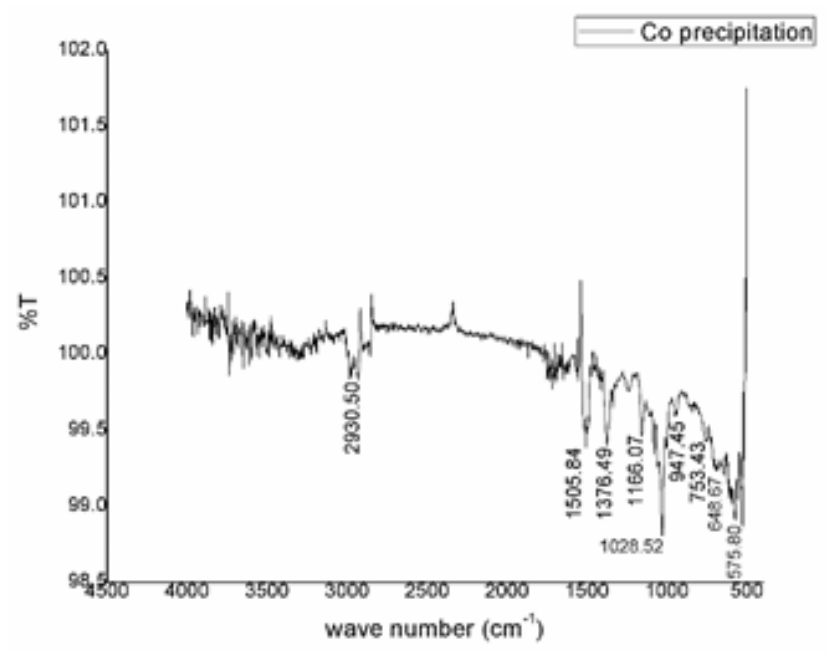

Figure 7: FT-IR spectrum of complexes prepared by co-precipitation method.

Pure Embelin shows peaks at $3290 \mathrm{~cm}^{-1}$ due to alcoholic O-H stretching, $2857 \mathrm{~cm}^{-1}$ and $2922 \mathrm{~cm}^{-1}$ due to stretching vibration of C-H bond, $1680 \mathrm{~cm}^{-1}$ by the presence of alkene and $1117 \mathrm{~cm}^{-1}, 1174 \mathrm{~cm}^{-1}$, $1320 \mathrm{~cm}^{-1}$ due to alcoholic C-O bond ${ }^{34,35}$ (Figure 7). $\beta$ cyclodextrin shows peaks at $3301 \mathrm{~cm}^{-1}, 1619 \mathrm{~cm}^{-1}, 1490$ $\mathrm{cm}^{-1}, 1320 \mathrm{~cm}^{-1}, 1360 \mathrm{~cm}^{-1}, 1150 \mathrm{~cm}^{-1}, 1028 \mathrm{~cm}^{-1}$ due to stretching of $\mathrm{O}-\mathrm{H}$ bond, an amide bond, in-plane $\mathrm{O}-\mathrm{H}$ bending, $\alpha-\mathrm{CH}_{2}$ bending, $\mathrm{O}-\mathrm{H}$ bending, $\mathrm{C}-\mathrm{C}-\mathrm{C}$ bending respectively ${ }^{36,37}$ (Figure 4). Physical mixture shows spectra which were superimposition of spectra of Embelin and $\beta$ - cyclodextrin with minor alterations indicating the absence of interaction ${ }^{38}$ (Figure 3). Complexes prepared by kneading method showed a shift in $2331 \mathrm{~cm}^{-1}, 1028$ $\mathrm{cm}^{-1}, 1619 \mathrm{~cm}^{-1}$ to $1611 \mathrm{~cm}^{-1}, 1320 \mathrm{~cm}^{-1}$ to $1336 \mathrm{~cm}^{-1}$, $1150 \mathrm{~cm}^{-1}$ to $1157 \mathrm{~cm}^{-1}$ which shows the peaks are more

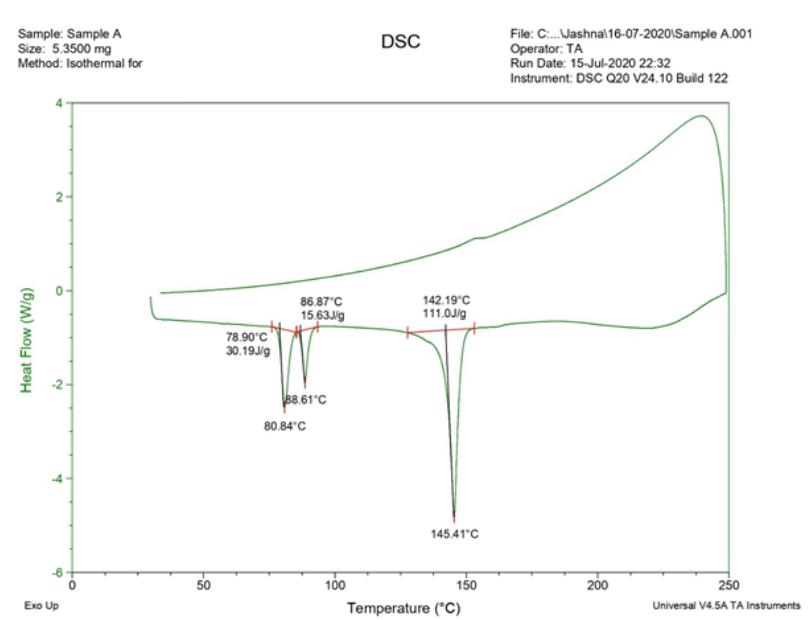

Figure 8: DSC of Embelin.

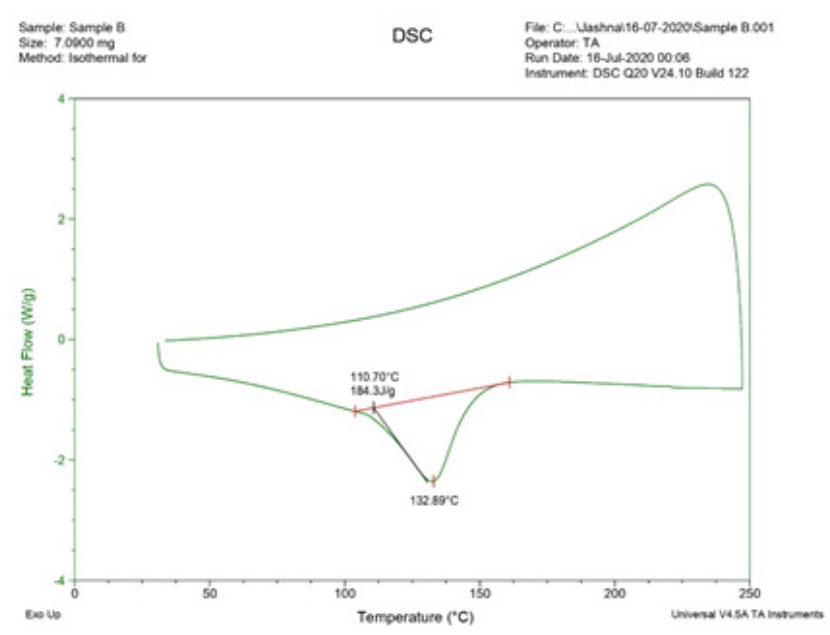

Figure 9: DSC of $\square$ cyclodextrin.

likely towards the peak of $\beta$ - cyclodextrin (Figure 5). Complexes prepared by co-precipitation method showed shift in $2830 \mathrm{~cm}^{-1}$ to $2930 \mathrm{~cm}^{-1}, 1602 \mathrm{~cm}^{-1}$ to $1505 \mathrm{~cm}^{-1}$, $1320 \mathrm{~cm}^{-1}$ to $1376 \mathrm{~cm}^{-1}, 1117 \mathrm{~cm}^{-1}$ to $1166 \mathrm{~cm}^{-1}$ (Figure 6). In comparison with peaks of Embelin, spectra of complexes showed changes in the position of peaks and a considerable decrease in intensity. This indicates an encapsulation of the benzoquinone ring of Embelin in $\beta$-cyclodextrin cavity. The spectrum of the physical mixture was similar to that of pure Embelin. Spectra of complexes prepared by kneading and co-precipitation method showed similarity to spectra of $\beta$ - cyclodextrin. All absorption peaks of cyclodextrin polymer can be found but all characteristic peaks of Embelin almost disappear. Only a faint $\mathrm{O}-\mathrm{H}$ and $\mathrm{C}-\mathrm{O}$ vibration were observed at the $3200 \mathrm{~cm}^{-1}$ and $1600 \mathrm{~cm}^{-1}$ range, which provides substantial evidence of the formation of the Embelin/ $\beta$ cyclodextrin inclusion complex. 


\begin{tabular}{|c|c|c|c|c|}
\hline \multicolumn{5}{|c|}{ Table 2: In vitro drug release study. } \\
\hline Time (min) & Embelin & Physical mixture & Kneading method & Co-precipitation method \\
\hline 0 & 0 & 0 & 0 & 0 \\
\hline 5 & $23.023 \pm 2.22$ & $30.412 \pm 2.02$ & $39.049 \pm 4.02$ & $42.116 \pm 3.54$ \\
\hline 10 & $26.189 \pm 3.28$ & $33.671 \pm 1.33$ & $48.421 \pm 3.88$ & $49.773 \pm 3.63$ \\
\hline 15 & $27.264 \pm 3.33$ & $40.188 \pm 2.41$ & $48.421 \pm 3.56$ & $53.602 \pm 3.75$ \\
\hline 30 & $30.434 \pm 2.24$ & $44.532 \pm 2.51$ & $53.107 \pm 3.21$ & $61.259 \pm 3.21$ \\
\hline 45 & $32.561 \pm 2.22$ & $49.963 \pm 2.21$ & $59.354 \pm 3.54$ & $67.640 \pm 4.11$ \\
\hline 60 & $33.643 \pm 1.91$ & $53.222 \pm 3.35$ & $64.040 \pm 3.63$ & $71.469 \pm 4.21$ \\
\hline 120 & $33.680 \pm 3.02$ & $59.739 \pm 2.45$ & $71.850 \pm 2.92$ & $77.850 \pm 3.53$ \\
\hline 180 & $34.764 \pm 2.31$ & $64.083 \pm 3.04$ & $76.536 \pm 3.75$ & $84.231 \pm 3.89$ \\
\hline 240 & $35.848 \pm 3.05$ & $65.169 \pm 2.99$ & $78.098 \pm 3.41$ & $89.336 \pm 3.91$ \\
\hline 300 & $39.028 \pm 2.35$ & $69.514 \pm 2.63$ & $85.908 \pm 3.22$ & $96.994 \pm 3.14$ \\
\hline
\end{tabular}

Min: minutes

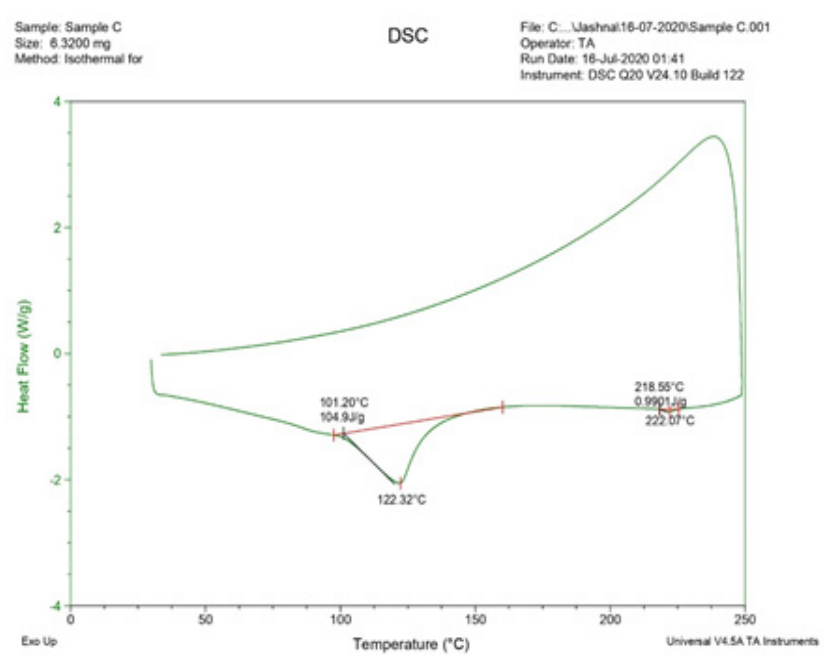

Figure 10: DSC of co-precipitation.

DSC is a thermal analysis technique that processes the temperature and heat flow related through transitions in materials as a function of temperature and time.

The DSC of Embelin exhibited three endothermic peaks at $86.87^{\circ} \mathrm{C}, 78.90^{\circ} \mathrm{C}$ and $142.19^{\circ} \mathrm{C}$ (Figure 8) resulting from loss of water, dehydration of the compound and melting point. $\beta$ cyclodextrin shows a characteristic endothermic peak at $110.70^{\circ} \mathrm{C}$ (Figure 9) which is its melting point. Complexes prepared by the co-precipitation method show peak at $101.20^{\circ} \mathrm{C}$ (Figure 10). The characteristic endothermic peak of Embelin corresponding to the melting point has disappeared which indicates that the Embelin is complexed or encapsulated in the hydrophobic cavity of $\beta$ cyclodextrin. SEM image (Figure 11) of complexes prepared by co-precipitation shows smooth surface and regular shape. This may be due to the complication of Embelin

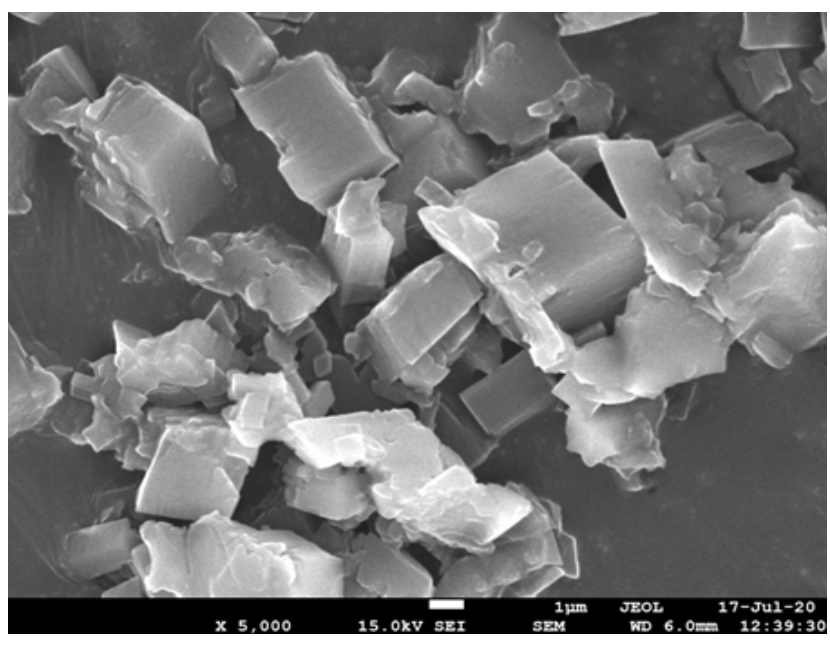

Figure 11: SEM image of complexes prepared by co-precipitation method.

in $\beta$ - cyclodextrin which is again confirmed by FT-IR and DSC analysis.

The dissolution study of pure Embelin, physical mixture and inclusion complexes were carried out. The inclusion complexes of Embelin with $\beta$ cyclodextrin could produce a considerable enhancement in the solubility of Embelin. Time to release $50 \%\left(\mathrm{t}_{50}\right)$ of Embelin was in the order $15 \mathrm{~min}, 30 \mathrm{~min}$ and $60 \mathrm{~min}$ for complexes prepared by co-precipitation, kneading method and physical mixture respectively (Figure 12). Complexes prepared by co-precipitation method showed $\mathrm{t}{ }_{90}$ (Time to release $90 \%$ ) value for Embelin as four hours. The cumulative drug release by physical mixture, complexes prepared by kneading method and pure Embelin at the fourth hour was $70 \%, 86 \%$ and $39 \%$ respectively. It is evident from the results that the degree of improvement in the dissolution rate depends upon the method of preparation. Complex formation at the molecular level 


\begin{tabular}{|c|c|c|}
\hline \multicolumn{3}{|c|}{ Table 3: Percent Antibacterial activity. } \\
\hline Organisms & E. coli & S. aureus \\
\hline Physical mixture & $30.43 \pm 0.2$ & $52.0 \pm 0.07$ \\
\hline Kneading method & $47.82 \pm 0.1$ & $87.2 \pm 0.2$ \\
\hline Co-precipitation method & $96.95 \pm 0.01$ & $97.6 \pm 0.02$ \\
\hline
\end{tabular}

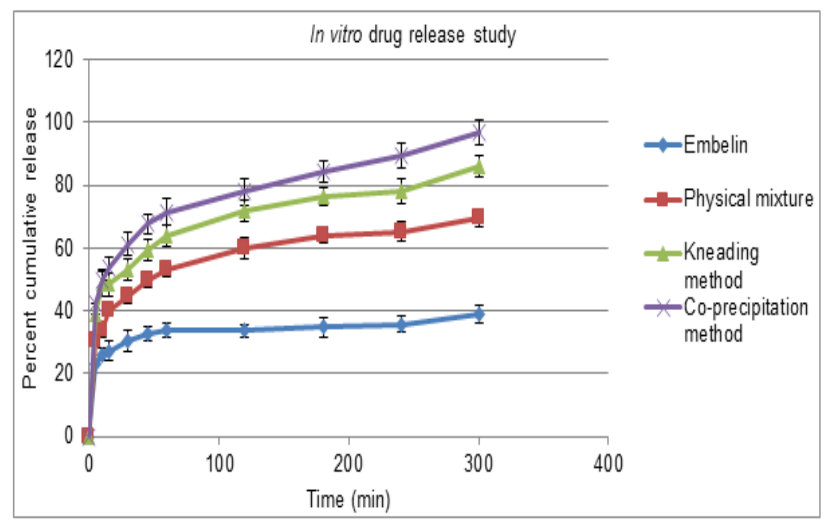

Figure 12: In vitro drug release study.

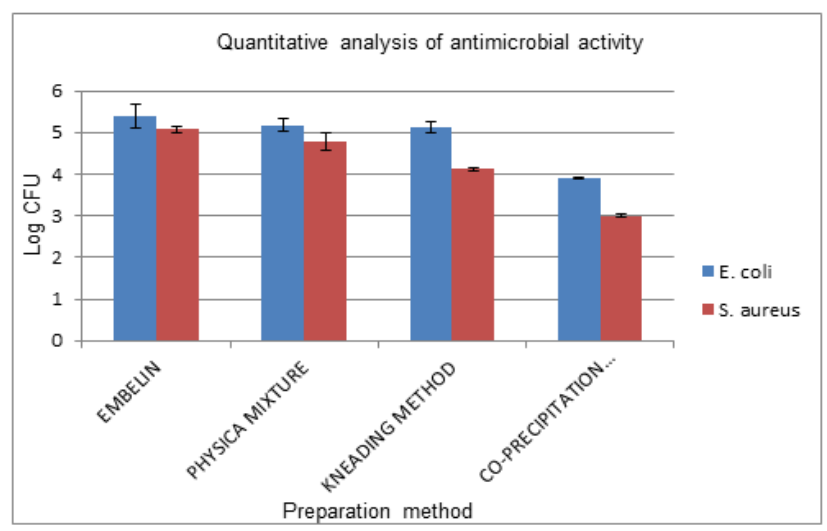

Figure 13: Antibacterial activity.

in the coprecipitation method may be the reason for its highest solubility. All the complexes could achieve improvement in wettability of Embelin due to the high aqueous solubility. ${ }^{29-39}$

The bioavailability of Embelin is $30 \pm 11 \%$. A toxicology study of Embelin on experimental rats reported that it is safe at a dose of $20 \mathrm{mg} / \mathrm{kg}$ body weight/day for 30 days. ${ }^{40}$ Enhancement of solubility and bioavailability by complexation can further reduce the dose of Embelin in its final formulation. So oral formulations based on complexes of Embelin are expected to have acceptable size.The antibacterial activity of pure Embelin and inclusion complexes was tested by using the viable cellcounting method. The inclusion complexes prepared from three methods were tested against two bacteria $E$. coli and S. aureus. Embelin shows significant antibacterial activity. ${ }^{41}$ Antimicrobial activity of Embelin, physical mixture and complexes were high on Gram-positive organisms in comparison to that on Gram-negative organisms. This is consistent with the literature reporting MIC of Embelin for S. aureus and E. coli is $20 \mu \mathrm{g} / \mathrm{ml}$ and $45 \mu \mathrm{g} / \mathrm{ml}$ respectively. ${ }^{6}$ This may be due to the presence of outer membrane in Gram-negative bacteria, the reason for their resistance to most antimicrobial agents. ${ }^{42-44}$ In comparison to Embelin, the antibacterial activity of complexes by physical method, kneading and co-precipitation method was $30 \pm 0.2 \%, 47 \pm 0.1 \%$ and $96 \pm 0.01 \%$ for E. coli and $52 \pm 0.07 \%, 87 \pm 0.2 \%$ and $97 \pm 0.02 \%$ for and $S$. aureus. Complexes prepared by the kneading method showed a $1 \log$ reduction in the number of $S$. aureus in comparison with EMB. But there was only a slight decrease in the number of $E$. coli as compared with EMB. Complexes prepared by the coprecipitation method showed $2 \log$ reductions in the number of $S$. aureus as compared to EMB whereas $1 \mathrm{log}$ reduction in the number of E. coli (Figure 13). This may be due to the formation of the inclusion complex in the right proportions in the co-precipitation method. This may be due to the formation of the inclusion complex in the right proportions in the co-precipitation method. In the co-precipitation method, inclusion complexes were formed at the molecular level as this method involves heat and stirring assisted bombardment of molecules with adequate energy. ${ }^{45}$ This can be interpreted in the light of literature that reports quinones having pharmacophores for antibacterial activities have functioned as substrates of bacterial efflux pumps. ${ }^{46}$ So usefulness of Embelin complexes for combining with other efflux pump inhibitors in the fight against antimicrobial resistance in bacterial infections has to be investigated. Further studies on molecular mechanisms of antimicrobial activity of Embelin complexes have to be carried out.

\section{CONCLUSION}

Phase solubility studies showed that stoichiometric ratio complexes of Embelin and $\beta$-cyclodextrin are 1:2. Inclusion complexes of Embelin were prepared by physical mixture, kneading and co-precipitation method. Complex formation was confirmed by FT-IR, DSC and SEM. Complexes prepared by the co-precipitation method showed fast and highest Embelin solubility. Antimicrobial studies confirmed that complexes prepared by kneading and co-precipitation methods showed more sensitivity to Gram-positive microorganisms. Complexes prepared from the co-precipitation method showed 100and 10-times reduction in the number of Gram-positive 
microorganisms and Gram-negative microorganisms respectively in comparison to Embelin. So, Embelin $\beta$ - cyclodextrin complexes have the potential for the development of Embelin dosage forms with enhanced biological activities.

\section{ACKNOWLEDGEMENT}

The authors are grateful to KSCSTE, Trivandrum for financial support by Student Project Grant.

\section{ABBREVIATIONS}

g/ml: Gram per milliliter; $\mathrm{mg} / \mathrm{ml}$ : Milligram per milliliter; ${ }^{\circ} \mathrm{C}$ : Degree centigrade; h: hours; min: minutes; $\alpha$ : Alpha; $\boldsymbol{\beta}$ : Beta; $\gamma$ : Gamma; v/v: Volume by volume; $\mathrm{ml}$ : Milliliter; $\mathrm{mM} / \mathrm{ml}$ : Milli mol per milliliter; $\mu \mathrm{m}$ : Micrometer; rpm: Revolutions per minute; min: Minute; nm: Nanometer; cm: Centimeter; mg: Milligram; kV: Kilovolt; CFU/ml: Colony-forming unit per milliliter; CD: Cyclodextrin; log: Logarithm.

\section{REFERENCES}

1. Kunnumakkara AB, Sailo BL, Banik K, Harsha C, Prasad S, Gupta SC, et al. Chronic diseases, inflammation and spices: How are they linked?. Journal of Translational Medicine. 2018;16(1):1-25.

2. Li Z, Chen SJ, Yu XA, Li J, Gao XM, He J, et al. Pharmacokinetic and bioavailability studies of embelin after intravenous and oral administration to rats. Evidence-Based Complementary and Alternative Medicine. 2019.

3. Kocak C, Kocak FE, Akcilar R, Isiklar OO, Kocak H, Bayat Z, et al. Molecular and biochemical evidence on the protective effects of embelin and carnosic acid in isoproterenol-induced acute myocardial injury in rats. Life Sciences. 2016;147:15-23.

4. Ko JH, Lee SG, Yang WM, Um JY, Sethi G, Mishra S, et al. The application of embelin for cancer prevention and therapy. Molecules. 2018;23(3):621.

5. Kumar K, Dhamotharan R, Kulkarni NM, Honnegowda S, Murugesan S. Embelin ameliorates dextran sodium sulfate-induced colitis in mice. International Immunopharmacology. 2011;11(6):724-31.

6. Radhakrishnan N, Gnanamani A, Mandal AB. A potential antibacterial agent Embelin, a natural benzoquinone extracted from Embelia ribes. Biology and Medicine. 2011;3(2):1-7.

7. Lal B, Mishra N. Importance of Embelia ribes: An update. International Journal of Pharmaceutical Sciences and Research. 2013;4(10):3823.

8. Mahendran S, Badami S, Ravi S, Thippeswamy BS, Veerapur VP. Synthesis and evaluation of analgesic and anti-inflammatory activities of most active free radical scavenging derivatives of Embelin-A Structure-Activity relationship. Chemical and Pharmaceutical Bulletin. 2011;59(8):913-9.

9. Mahendran S, Badami S, Maithili V. Evaluation of antidiabetic effect of embelin from Embelia ribes in alloxan induced diabetes in rats. Biomedicine and Preventive Nutrition. 2011;1(1):25-31.

10. Kundap UP, Bhuvanendran S, Kumari Y, Othman I, Shaikh M. Plant derived phytocompound, embelin in CNS disorders: A systematic review. Frontiers in Pharmacology. 2017; 8:76.

11. Swamy HK, Krishna V, Shankarmurthy K, Rahiman BA, Mankani KL, Mahadevan $\mathrm{KM}$, et al. Wound healing activity of embelin isolated from the ethanol extract of leaves of Embelia ribes Burm. Journal of Ethnopharmacology. 2007;109(3):529-34.

12. Radhakrishnan N, Gnanamani A. 2, 5-dihydroxy-3-undecyl-1, 4-benzoquinone (Embelin)-A second solid gold of India-A Review. International Journal Pharmacy and Pharmaceutical Sciences. 2014;6:23-30.
13. Neeraj, Mittal V, Nanda A. Development and in vitro evaluation of selfemulsifying formulation for embelin. International Journal of Pharmaceutical Sciences and Research. 2018;9(2):633-41.

14. Kaur V, Hallan SS, Nidhi AN, Mishra N. Isolation of embelin from and evaluation of its anti-cancer potential in Embelia ribes breast cancer. Asian Journal of Pharmacy and Pharmacology. 2015;1(1):33-9.

15. Loftsson T, Brewster ME. Pharmaceutical applications of cyclodextrins: Basic science and product development. Journal of Pharmacy and Pharmacology. 2010;62(11):1607-21.

16. Brewster ME, Loftsson T. Cyclodextrins as pharmaceutical solubilizers. Advanced Drug Delivery Reviews. 2007;59(7):645-66.

17. Suvarna V, Gujar P, Murahari M. Complexation of phytochemicals with cyclodextrin derivatives: An insight. Biomedicine and Pharmacotherapy. 2017;88:1122-44.

18. Singh R, Bharti N, Madan J, Hiremath SN. Characterization of cyclodextrin inclusion complexes: A review. J Pharm Sci Technol. 2010;2(3):171-83.

19. Fateminasab F, Bordbar AK, Shityakov S. Detailed chemical characterization and molecular modeling of serotonin inclusion complex with unmodified ß-cyclodextrin. Heliyon. 2019;5(4):e01405.

20. Saokham P, Muankaew C, Jansook P, Loftsson T. Solubility of cyclodextrins and drug/cyclodextrin complexes. Molecules. 2018;23(5):1161.

21. Loftsson $T$, Jarho $P$, Masson $M$, Järvinen $T$. Cyclodextrins in drug delivery. Expert Opinion on Drug Delivery. 2005;2(2):335-51.

22. Patil JS, Devi K, Sarasija S. Formulation and evaluation of novel spray-dried alginate microspheres as pulmonary delivery systems of rifampicin in rats. Indian J Pharm Edu Res. 2015;49(4):320-8.

23. Kalyanappa S, Krishna MR, Goli D. Design and in vitro Evaluation of a Novel Sustained Release Double Layered Tablets of Lornoxicam by using semi synthetic polymers. Indian J Pharm Educ Res. 2015;49:281-91.

24. Jacob $S$, Nair AB. Cyclodextrin complexes: Perspective from drug delivery and formulation. Drug Development Research. 2018;79(5):201-17.

25. Sethuraman N, Shanmuganathan S, Sandhya K, Anbarasan B. Design, development and characterization of nano structured lipid carrier for topical delivery of aceclofenac. Indian Journal of Pharmaceutical Education and Research. 2018;52(4):581-6.

26. Higuchi TK. A phase solubility technique. Adv Anal Chem Instrum. 1965;4:117211.

27. Waleczek KJ, Marques HC, Hempel B, Schmidt PC. Phase solubility studies of pure (-)- $\alpha$-bisabolol and camomile essential oil with $\beta$-cyclodextrin. European Journal of Pharmaceutics and Biopharmaceutics. 2003;55(2):247-51.

28. Tablet C, Matei I, Hillebrand M. The determination of the stoichiometry of cyclodextrin inclusion complexes by spectral methods: Possibilities and limitations. Stoichiometry and Research-The Importance of Quantity in Biomedicine. 2012;47-76.

29. Ghosh A, Biswas S, Ghosh T. Preparation and evaluation of silymarin $\beta$-cyclodextrin molecular inclusion complexes. Journal of Young Pharmacists. 2011;3(3):205-10.

30. Yadav VR, Suresh S, Devi K, Yadav S. Effect of cyclodextrin complexation of curcumin on its solubility and antiangiogenic and anti-inflammatory activity in rat colitis model. Aaps Pharmscitech. 2009;10(3):752.

31. Sapana BB, Shashikant DN. Preparation and characterisation of [beta]cyclodextrin nebivolol inclusion complex. International Journal of Pharmaceutical Sciences and Research. 2015;6(5):2205.

32. Forbes $\mathrm{B}$, Richer $\mathrm{NH}$, Buttini $\mathrm{F}$. Dissolution: A critical performance characteristic of inhaled products?. Pulmonary Drug Delivery: Advances and Challenges. John Wiley and Sons Ltd, Chichester. 2015;223-40.

33. Aytac Z, Yildiz ZI, Kayaci-Senirmak F, Tekinay T, Uyar T. Electrospinning of cyclodextrin/linalool-inclusion complex nanofibers: Fast-dissolving nanofibrous web with prolonged release and antibacterial activity. Food Chemistry. 2017;231:192-201.

34. Sharma A, Kaur N, Sharma S, Sharma A, Rathore MS, Ajay K, et al. Embelinloaded guar gum microparticles for the management of ulcerative colitis. Journal of Microencapsulation. 2018;35(2):181-91.

35. Badamaranahalli SS, Kopparam M, Bhagawati ST, Durg S. Embelin lipid nanospheres for enhanced treatment of ulcerative colitis-Preparation, characterization and in vivo evaluation. European Journal of Pharmaceutical Sciences. 2015;76:73-82. 
36. Raba B, Rabadiya B, Thakkar V, Rabadiya P. Drug-excipient interaction and solubility enhancement study of Simvastatin. International Journal of Pharmaceutical Research and Bioscience. 2013;2(1):168-85.

37. Kulkarni A, Dias R, Ghorpade V. Freeze dried multicomponent inclusion complexes of quercetin: Physicochemical evaluation and pharmacodynamic study. Journal of Research in Pharmacy. 2019;23(3).

38. Ruan LP, Yu BY, Fu GM, Zhu DN. Improving the solubility of ampelopsin by solid dispersions and inclusion complexes. Journal of Pharmaceutical and Biomedical Analysis. 2005;38(3):457-64.

39. Rudrangi SR, Kaialy W, Ghori MU, Trivedi V, Snowden MJ, Alexander BD. Solid-state flurbiprofen and methyl- $\beta$-cyclodextrin inclusion complexes prepared using a single-step, organic solvent-free supercritical fluid process. European Journal of Pharmaceutics and Biopharmaceutics. 2016;104:16470.

40. Radhakrishnan N, Gnanamani A. 2, 5-dihydroxy-3-undecyl-1, 4-benzoquinone (Embelin)-A second solid gold of India-A Review. Int J Pharm Pharmacol Sci. 2014;6:23-30
41. Chitra M, Shyamala DCS, Sukumar E. Antibacterial activity of embelin. Fitoterapia. 2003;74(4):401-3.

42. Breijyeh Z, Jubeh B, Karaman R. Resistance of Gram-negative bacteria to current antibacterial agents and approaches to resolve it. Molecules. 2020;25(6):1340.

43. Karaman R, Jubeh B, Breijyeh Z. Resistance of Gram-Positive Bacteria to Current Antibacterial Agents and Overcoming Approaches. Molecules. 2020;25(12):2888.

44. Miller SI. Antibiotic resistance and regulation of the gram-negative bacterial outer membrane barrier by host innate immune molecules. MBio. 2016;7(5).

45. Sapkal NP, Kilor VA, Bhursari KP, Daud AS. Evaluation of some methods for preparing gliclazide- $\beta$-cyclodextrin inclusion complexes. Tropical Journal of Pharmaceutical Research. 2007;6(4):833-40.

46. Omosa LK, Midiwo JO, Mbaveng AT, Tankeo SB, Seukep JA, Voukeng IK, et al. Antibacterial activities and structure-activity relationships of a panel of 48 compounds from Kenyan plants against multidrug resistant phenotypes. Springer Plus. 2016;5(1):901

\section{PICTORIAL ABSTRACT}

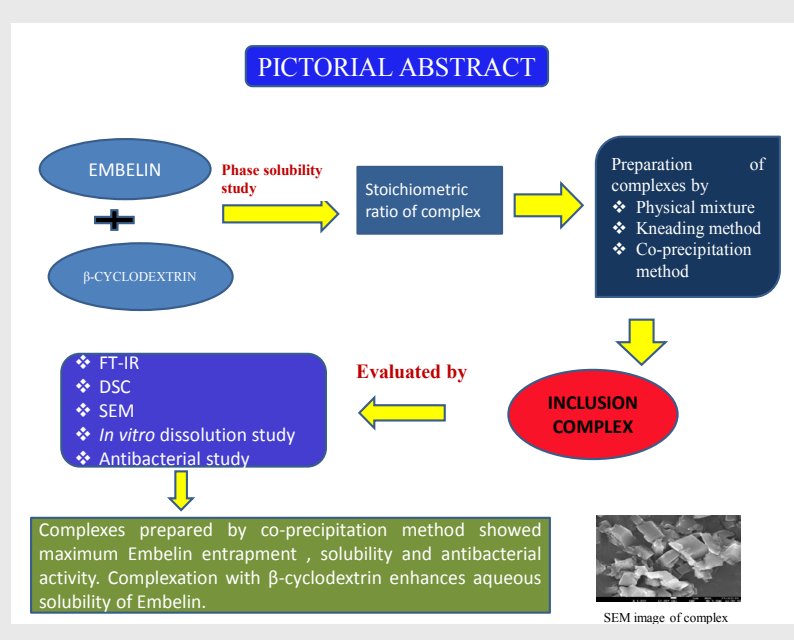

\section{SUMMARY}

The present study aims to improve the water solubility and rate of dissolution of Embelin by the preparation of inclusion complexes with $\beta$-cyclodextrin. Inclusion complexes were prepared by kneading and coprecipitation methods. Fourier-Transform Infrared (FT-IR) spectroscopy and in vitro dissolution study were used to characterize the complexes. Complexes prepared by the co-precipitation method were also analyzed by Differential scanning calorimetry (DSC) and Scanning electron microscopy (SEM). Antimicrobial studies of complexes against Staphylococcus aureus and Escherichia coli were carried out by colony counting method. Phase solubility study showed Embelin forms complex with $\beta$-cyclodextrin in the ratio $1: 2$. FT-IR, DSC and SEM confirmed the formation of a complex of Embelin with $\beta$-cyclodextrin. Complexes of Embelin prepared by co-precipitation method resulted in the largest percent drug content, enhanced aqueous solubility and antibacterial activity.

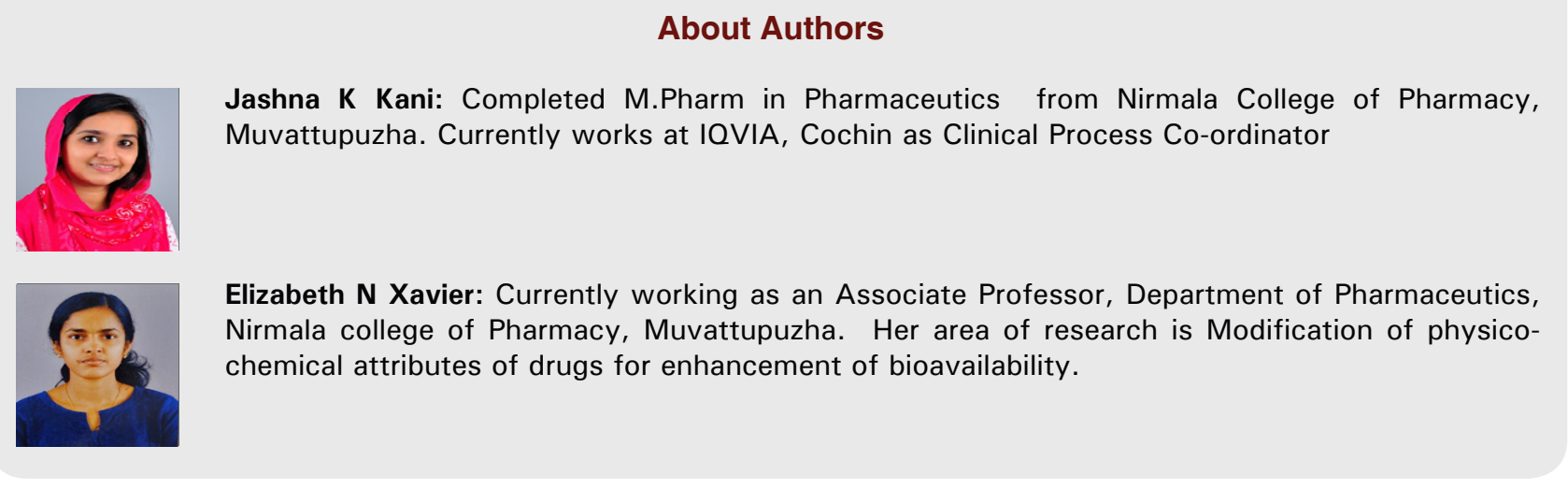

Cite this article: Kani JK, Xavier EN. Solubility Enhancement of Embelin by Complexation with Beta Cyclodextrin. Indian J of Pharmaceutical Education and Research. 2021;55(2s):s405-s413. 